\title{
Does Radiation Dose to Gastric Fundus during Neoadjuvant Chemoradiotherapy for Esophageal Carcinoma Have an Impact on Postoperative Anastomotic Leak?
}

\author{
Nikhila Radhakrishna ${ }^{a}$ Shyama Prem Sudha ${ }^{b}$ Raja Kalayarasan ${ }^{c}$ \\ Prasanth Penumadud

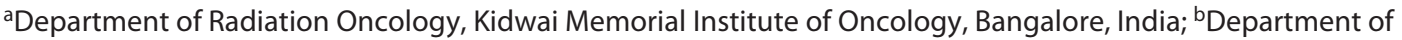 \\ Radiation Oncology, Jawaharlal Institute of Post Graduate Medical Education and Research (JIPMER), An Institution \\ of National Importance, Government of India, Puducherry, India; 'Department of Surgical Gastroenterology, \\ Jawaharlal Institute of Post Graduate Medical Education and Research (JIPMER), An Institution of National

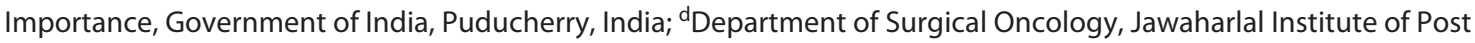 \\ Graduate Medical Education and Research (JIPMER), An Institution of National Importance, Government of India, \\ Puducherry, India
}

\section{Keywords}

Gastric fundus · Esophageal carcinoma · Anastomotic leak ·

Neoadjuvant chemoradiotherapy · Radiation dose

\begin{abstract}
Background: Radiation dose received by the gastric fundus (GF) in neoadjuvant chemoradiotherapy (NACRT) may influence the development of postoperative anastomotic leak $(\mathrm{AL})$ in the management of resectable esophageal carcinoma (EC) by trimodality therapy. The present study aims to evaluate dose-volume parameters of the GF and their association with occurrence of AL in EC. Materials and Methods: A retrospective analysis was performed of 27 patients with EC who underwent NACRT followed by esophagectomy with cervical esophagogastric anastomosis between January 2015 and July 2018. The GF was retrospectively contoured; dose-volume parameters of the GF were recorded. Postoperative $A L$ was identified from surgical records. Logistic regression analysis was used to identify risk factors associated with AL. Results: The mean age of the patients was $51 \pm 10.5$ years; $56 \%(15 / 27)$ had involvement of lower $1 / 3$ esophagus, 10/27 (37\%) midthoracic esophagus, and 2/27 (7\%) upper thoracic esophagus; $40 \%$ (11/27) patients developed post-
\end{abstract}

karger@karger.com www.karger.com/gat

Karger $\stackrel{\text { ' }}{5}$

GOPEN ACCESS
(C) 2021 The Author(s)

Published by S. Karger AG, Basel

This article is licensed under the Creative Commons AttributionNonCommercial-NoDerivatives 4.0 International License (CC BYNC-ND) (http://www.karger.com/Services/OpenAccessLicense) Usage and distribution for commercial purposes as well as any distribution of modified material requires written permission. operative $A L$ and $7 / 11$ had distal and 4/11 had mid thoracic esophageal lesions. Four of five $(80 \%)$ patients treated by 3-dimensional conformal radiotherapy versus $7 / 22$ (32\%) patients treated by volumetric modulated arc therapy developed AL $(p=0.12)$. Univariate logistic regression revealed no significant correlation between $D_{\text {mean }}, D_{\text {max }}, \mathrm{V} 20, \mathrm{~V} 25, \mathrm{~V} 30$, V35, D50, and AL. $8 / 27$ patients underwent ischemic preconditioning of gastric conduit, and 2/8 had AL; 19/27 did not undergo preconditioning, and $9 / 19$ patients experienced $\mathrm{AL}$ $(p=0.4)$. Conclusion: There was no significant negative impact of the dose received by the GF in NACRT upon AL rates. Further studies with a larger sample size are required to clarify this issue.

(c) 2021 The Author(s)

Published by S. Karger AG, Basel

\section{Introduction}

Neoadjuvant chemoradiotherapy (NACRT) followed by esophagectomy is the standard of care for resectable esophageal carcinoma [1]. The overall survival benefit of NACRT is well established [1-4]. Though refinements in surgical techniques and improved perioperative management have led to a decrease in postoperative complica- 
tions, NACRT is associated with an increase in postoperative morbidity and mortality $[3,4]$. Anastomotic leak (AL) of the esophagogastric anastomosis is one of the major complications, which negatively impacts the quality of life and surgical outcome. In various studies, the incidence of AL ranged from 5 to $40 \%$ [5]. The mortality associated with leak ranged between 11 and 14\% [6]. Risk factors that influenced the development of AL include the anastomotic technique (hand sewn vs. stapled vs. hybrid) [7], location of the anastomosis (neck vs. chest) [8-10], type of conduit (stomach vs. colon vs. small bowel) [11], neoadjuvant therapy $[1,2,12-14]$, and comorbid conditions $[11,15]$. In a single-center retrospective review of 393 esophagectomy patients, neoadjuvant therapy was associated with an odds ratio of 2.2 (OR 2.2, 95\% CI 1.14.5) for developing AL [11].

The stomach is the best choice for conduit, and the gastric fundus (GF) is the ideal site for anastomosis due to least tension at this site. Dose received by the GF in neoadjuvant radiation is, therefore, important and may have a role in the development of an AL. Whether it negatively impacts the development of leak is unclear with conflicting evidences [16, 17]. Our retrospective study was performed to shed light on the possibility of considering the GF as an organ at risk and to evaluate the relationship between the doses received by the GF and the occurrence of AL.

\section{Materials and Methods}

\section{Study Population}

A retrospective analysis of patients with esophageal or gastroesophageal junction cancer (Sievert I and II) who underwent NACRT followed by transthoracic esophagectomy between January 2015 and July 2018 at our tertiary referral center was performed. All patients had biopsy-proven resectable carcinoma with no evidence of distant metastases. Patients who underwent transhiatal esophagectomy, salvage esophagectomy, or nonelective operation and patients in whom no gastric conduit reconstruction was performed were excluded. Ethical clearance was obtained from the institutional Ethics Committee.

\section{Chemoradiotherapy}

Tumor volumes were delineated on a contrast-enhanced simulation computerized tomography scan, using the information from endoscopy and diagnostic contrast-enhanced computerized tomography based on the contouring guidelines provided by $\mathrm{Wu}$ et al. [18]; 41.4-45 Gray (Gy) in 23-25 fractions was delivered at 1.8 Gy per fraction over 5 weeks by volumetric modulated arc therapy or 3-dimensional conformal radiotherapy on Varian Clinac IX, planned on Eclipse 10.1.

Concurrent chemotherapy was administered as per CROSS protocol [1] on days $1,8,15,22$, and 29 using paclitaxel (50 mg/ $\mathrm{m}^{2}$ ) and carboplatin with AUC $=2 \mathrm{mg} / \mathrm{mL} / \mathrm{min}$. Weekly hemogram, serum electrolytes, renal functions, and liver functions were monitored. Chemotherapy was delayed by 1 week if ANC $<1,000$, $\mathrm{Hb}<9 \mathrm{~g} \%$, and platelets $<50,000$. Chemotherapy was withheld if febrile neutropenia set in or the patient developed bleeding requiring $>2$ platelet transfusions.

\section{Surgery}

Feeding jejunostomy was performed for patients with grade $3 / 4$ dysphagia. Eight patients underwent ischemic preconditioning of the stomach at the time of feeding jejunostomy.

All patients underwent transthoracic esophagectomy with extended 2-field lymph node dissection and cervical esophagogastric anastomosis using the modified Orringer technique, 6-8 weeks after completion of NACRT. The stomach was tubularized, and the gastric conduit was brought through the posterior mediastinum into the neck. Esophagogastric anastomosis was performed by staplers or a hand-sewn technique. A 75-mm linear cutter was used to create a gastric conduit $4-5 \mathrm{~cm}$ wide, and the gastric conduit staple line was oversewn by hand. A cervical esophagogastric anastomosis was performed with either an end-to-side with handsewn continuous sutures (3-0 PDS) in monolayer or a posterior layer stapled and anterior layer with hand-sewn interrupted sutures.

AL was defined as "full-thickness defects involving the esophagus, anastomosis, staple line, or conduit, irrespective of the presentation or method of identification" as per the Esophagectomy Complications Consensus Group (ECCG) [19]. All patients underwent a contrast gastrografin swallow study for the diagnosis of AL between postoperative days 7-10. The results were documented, and surgical interventions were carried out, when clinically indicated.

\section{Retrospective Contouring}

The contours and plans of 27 patients were retrieved. The GF was delineated according to the recommendations by Goense et al. [12]. The superiormost sections of the stomach, visible within the dome of the diaphragm, were determined on the axial CT slices of $3 \mathrm{~mm}$ thickness. From that level, the gastric contour was delineated in 4 consecutive axial sections in the caudal direction. The resulting structure in 3 dimensions was defined as the GF (Fig. 1).

\section{Plan Evaluation}

From the executed plans for each of the patients, the mean dose $\left(D_{\text {mean }}\right)$ received by the GF, maximum dose $\left(D_{\max }\right)$ received by the GF, volume receiving $20 \mathrm{~Gy}$ (V20), V25, V30, and V35, and dose received by $50 \%$ of the volume of the GF (D50) were computed using the dose-volume histogram. Whether the anastomosis was in the field of radiation or not was also documented.

\section{Statistical Methods}

Dosimetric parameters were expressed with mean and standard deviation. Fisher's test, Student's $t$ test, and Mann-Whitney $\mathrm{U}$ test were used to compare categorical, parametric, and nonparametric parameters. Univariable logistic regression models were used to analyze whether the different radiation dose and volume characteristics of the GF influenced the risk of AL. If the radiation dose parameters were to be found significantly related to AL, multivariable logistic regression would be used to assess the risk factors associated with AL. Statistical tests were performed using Stata version 14.0 , and $p$ value $<0.05$ was considered as significant. 
Fig. 1. a Axial section of the planning CT scan showing the contoured GF (white arrow). $\mathbf{b}$ Coronal section of the planning CT scan showing the contoured GF (white arrow). GF, gastric fundus; CT, computed tomography.
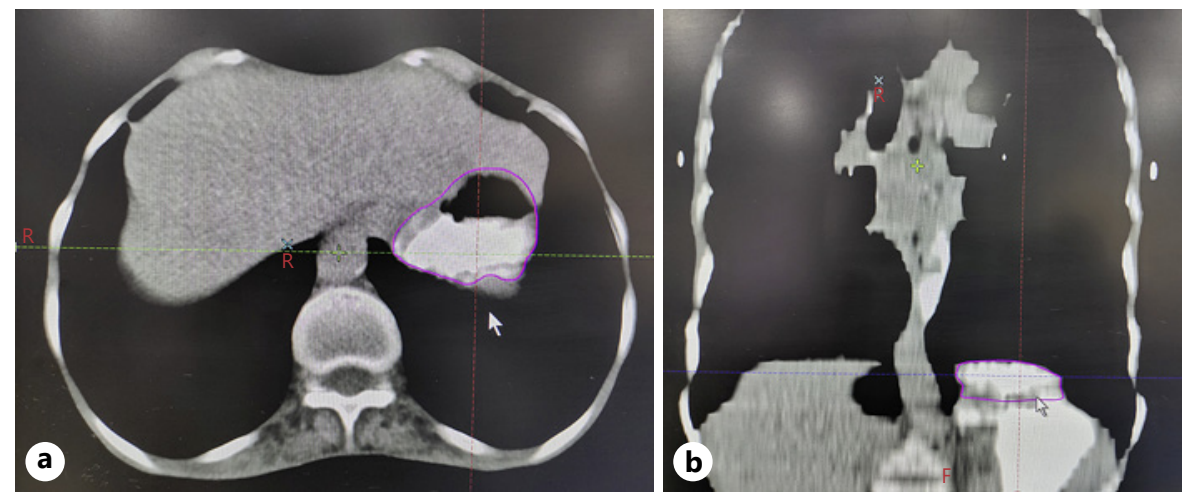

\section{Results}

Records of 47 patients diagnosed with esophageal carcinoma, who have received NACRT and underwent surgery between 2015 and 2018, were available for retrospective analysis. Of these, 13 patients underwent chemoradiation in other hospitals owing to waiting periods and were, hence, excluded from dosimetric analysis. Three patients did not complete NACRT; 2 refused surgery, 1 died after NACRT, and 1 patient developed omental deposits after NACRT. Thus, the remaining 27 records were used for analysis. The baseline characteristics have been described in Table 1.

The age of the patients ranged from 30 to 70 years (mean $=51$ years; $\mathrm{SD}=10.5)$. The majority of the patients (23/27 [85\%]) had squamous cell carcinoma, while 15\% $(4 / 27)$ had adenocarcinoma. $30 \%$ of the patients had T3 tumors, while $70 \%$ had T4 tumors. $52 \%$ had N0 disease, $40.7 \%$ had N1, and 7.4\% had N2 disease. 15/27 (56\%) patients had involvement of lower $1 / 3$ of the esophagus, $10 / 27$ (37\%) had involvement of the midthoracic esophagus, and $2 / 27$ (7\%) had lesion involving the upper thoracic esophagus. $22 / 27(81.5 \%)$ of the patients received volumetric modulated arc radiation, while 5/27 (18.5\%) received $3 \mathrm{D}$ conformal radiation.

All 27 patients underwent thoracolaparoscopic esophagectomy with 2-field esophagectomy and cervical esophagogastric anastomosis. 8/27 patients had undergone gastric ischemic preconditioning at the time of FJ. The mean duration between completion of NACRT and surgery was $54 \pm 11$ days.

The mean volume of the contoured fundus was $21.78 \pm 13.62 \mathrm{cc} .11 / 27$ (40\%) patients developed postoperative AL, among which 7 patients had distal third and 4 patients had middle esophageal lesions. Four of five patients treated by 3 -dimensional conformal radiothera-
Table 1. Baseline characteristics

Characteristics

With AL Without AL $(n=11) \quad(n=16)$

Gender

Female

Male

Age, years

ECOG PS

1

2

BMI

Level of lesion

Upper thoracic

Mid thoracic

Lower thoracic

Clinical T stage

cT1

cT2

cT3

cT4

Clinical $\mathrm{N}$ stage

$\mathrm{cN} 0$

$\mathrm{cN} 1$

$\mathrm{cN} 2$

$\mathrm{cN} 3$

Tumor histology

Squamous cell carcinoma $\quad 10 \quad 13$

Adenocarcinoma

Radiation technique

VMAT

3DCRT

Ischemic preconditioning

Performed

$\begin{array}{cc}6 & 10 \\ 5 & 6 \\ 47 \pm 8 & 53 \pm 10 \\ 5 & 14 \\ 6 & 2\end{array}$

$18.68 \pm 2.47 \quad 19.65 \pm 1.85$

Not performed

Gap between NACRT and surgery, days

$\mathrm{AL}$, anastomotic leak; VMAT, volumetric modulated arc therapy; 3DCRT, 3-dimensional conformal radiotherapy; NACRT, neoadjuvant chemoradiotherapy. 
Table 2. Dose-volume parameters for the GF as an organ at risk

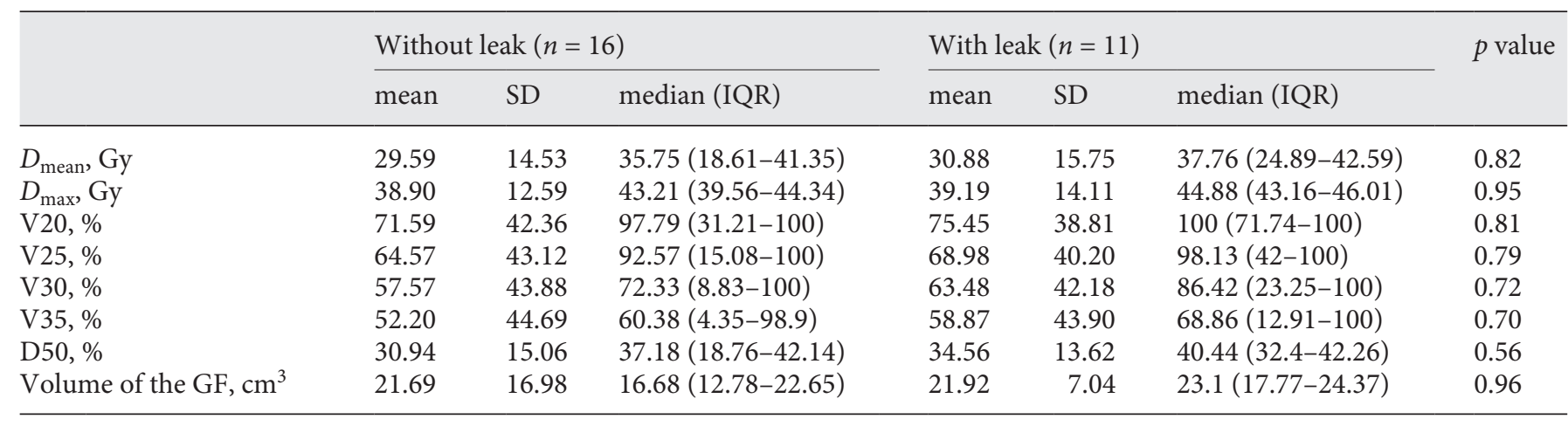

GF, gastric fundus; IQR, interquartile range

Table 3. Logistic regression analysis anastomotic leak versus dosimetric parameters

\begin{tabular}{llll}
\hline Dosimetric parameters & OR & CI & $p$ value \\
\hline$D_{\text {mean }}$ & 1.006 & $0.95-1.06$ & 0.81 \\
$D_{\max }$ & 1.001 & $0.94-1.06$ & 0.95 \\
V20 & 1.002 & $0.98-1.02$ & 0.8 \\
V25 & 1.002 & $0.98-1.02$ & 0.78 \\
V30 & 1.003 & $0.98-1.02$ & 0.72 \\
V35 & 1.003 & $0.98-1.02$ & 0.69 \\
D50 & 1.019 & $0.95-1.08$ & 0.54 \\
Volume & 1.001 & $0.94-1.06$ & 0.96 \\
\hline
\end{tabular}

OR, odds ratio; CI, confidence interval.

py developed leaks, whereas only $7 / 22$ patients treated by volumetric modulated arc therapy developed $\mathrm{AL}(p=$ 0.12 ).

There was no statistically significant difference between the dose-volume parameters of the GF in patients with AL versus those without AL (Table 2). Univariate logistic regression studies revealed no significant correlation between the dose-volume parameters and the leak rates (Table 3). Subgroup analysis to study the impact of the radiotherapy technique on the dose-volume parameters could not demonstrate a significant difference in the dose-volume parameters of the GF with respect to technique (Table 4). 8/27 patients underwent ischemic preconditioning of the gastric conduit, out of which only 2 patients had a postop AL. 19/27 patients did not undergo any preconditioning of the gastric conduit, out of which 9 experienced AL. However, a statistically significant benefit could not be established (Fisher exact test $p=0.4$ ) (Table 5). Multivariate analysis was not performed since none of the factors were significant on univariate analysis.

\section{Discussion}

In our study, we evaluated the relationship between the dose received by the GF and the occurrence of AL in patients with esophageal cancer treated with NACRT followed by transthoracic esophagectomy with gastric tube reconstruction and cervical anastomosis. Overall, 40\% (11/27) of our patients developed AL. In our study, several dose parameters which were postulated to have an impact on AL did not influence AL rates.

$\mathrm{AL}$ is defined as a disruption of the esophagogastric anastomosis which is diagnosed by radiographic examination using contrast, endoscopy, or clinical signs and symptoms. AL is a common complication following esophagectomy with the incidence ranging between 10 and $25 \%$ for cervical and 3-25\% for intrathoracic anastomoses $[1,5,10-14]$. ALs are associated with severe morbidity and mortality. The reported mortality rates among patients who develop AL range between 11 and 14\% [6].

Factors which influence the development of AL include the anastomotic technique (hand sewn vs. stapled vs. hybrid) [7], site of the anastomosis (cervical vs. thoracic) [8-10], the type of conduit used for anastomosis (stomach vs. colon vs. small bowel) [11], and NACRT [1, 2, 12-14]. All our patients underwent NACRT and underwent cervical anastomosis using the stomach as the conduit. A retrospective analysis by Morita et al. [13] showed that AL developed more frequently in patients who received NACRT than in the patients who under- 
Table 4. Subgroup analysis of dose-volume parameters for the GF of patients treated by 3DCRT/VMAT versus anastomotic leak

\begin{tabular}{|c|c|c|c|c|c|c|}
\hline & \multicolumn{2}{|l|}{ With leak $(n=11)$} & \multirow{2}{*}{$\begin{array}{l}\text { Mann- } \\
\text { Whitney U } \\
p \text { value }\end{array}$} & \multicolumn{2}{|l|}{ Without leak $(n=16)$} & \multirow{2}{*}{$\begin{array}{l}\text { Mann- } \\
\text { Whitney U } \\
p \text { value }\end{array}$} \\
\hline & $\begin{array}{l}\text { VMAT }(n=7) \\
\text { median (IQR) }\end{array}$ & $\begin{array}{l}\text { 3DCRT }(n=4), \\
\text { median (IQR) }\end{array}$ & & $\begin{array}{l}\text { VMAT } \\
(n=15), \\
\text { median (IQR) }\end{array}$ & $\begin{array}{l}\text { 3DCRT } \\
(n=1), \\
\text { median }\end{array}$ & \\
\hline$D_{\text {mean }}, \mathrm{Gy}$ & $37.76(26.98-42.59)$ & $22.25(2.00-44.14)$ & 0.78 & $36.23(20.79-40.1)$ & 1.23 & 0.12 \\
\hline$D_{\max }, \mathrm{Gy}$ & $44.94(43.83-46.08)$ & $33.62(7.05-45.13)$ & 0.10 & $43.27(41.08-44.62)$ & 1.85 & 0.12 \\
\hline $\mathrm{V} 20, \%$ & $100(75.5-100)$ & $50(0-100)$ & 0.47 & $98(42.43-100)$ & 0 & 0.17 \\
\hline $\mathrm{V} 25, \%$ & $98.13(53.45-100)$ & $50(0-100)$ & 0.61 & $93.11(20.97-100)$ & 0 & 0.17 \\
\hline V30, \% & $86.42(34.5-100)$ & $50(0-100)$ & 0.61 & $72.4(12.47-100)$ & 0 & 0.18 \\
\hline V35, \% & $68.86(20.04-100)$ & $50(0-100)$ & 0.62 & $65.16(5.75-99)$ & 0 & 0.19 \\
\hline Volume of the GF, $\mathrm{cm}^{3}$ & $23.1(14.22-24.24)$ & $22.96(18.36-35.07)$ & 0.31 & $16.1(12.33-24.34)$ & 19.53 & 0.75 \\
\hline
\end{tabular}

GF, gastric fundus; 3DCRT, 3-dimensional conformal radiotherapy; VMAT, volumetric modulated arc therapy; IQR, interquartile range.

Table 5. Subgroup analysis for patients with and without ischemic preconditioning versus anastomotic leak

\begin{tabular}{lcll}
\hline Ischemic preconditioning & $\begin{array}{l}\text { Patients } \\
\text { with AL }\end{array}$ & $\begin{array}{l}\text { Patients } \\
\text { without AL }\end{array}$ & $\begin{array}{l}\text { Fisher test } \\
p \text { value }\end{array}$ \\
\hline Performed & 2 & 6 & 0.40 \\
Not performed & 9 & 10 & \\
\hline Total & 11 & 16 & \\
\hline
\end{tabular}

$\mathrm{AL}$, anastomotic leak.

went surgery alone ( 28 vs. $17 \%$, respectively, $p<0.01$ ). The CROSS study demonstrated a similar difference of 22 versus $16 \%$ between NACRT and surgery-alone cohorts [1]. Goense et al. [12] had a leak rate of $26 \%$ in their study of 97 patients who received NACRT. AL was identified in $40 \%$ of patients in our study. The leak rates in our study were higher than those reported in the literature.

Since the stomach is used as a conduit for anastomosis and NACRT showed higher leak rates, the possibility of considering the dose received by the GF as a predictor for AL evolved. Goense et al. [12] studied 97 patients who received $41.4 \mathrm{~Gy}$ in 23 fractions and paclitaxel/carboplatin-based NACRT followed by transthoracic esophagectomy with 2-field lymphadenectomy and cervical anastomosis using a gastric conduit. AL was identified in 26\% (25/97) of the patients. A mean dose more than 31.4 Gy was associated with leakage rates of 43 versus $15 \%$ for $<31.4$ Gy with adjusted odds ratio 1.05 per 1 -Gy increase, $95 \%$ confidence interval: 1.002-1.10, and $p=0.043$. In our study, the $\mathrm{D}_{\text {mean }}$ was $29.6 \pm 14.5 \mathrm{~Gy}$ in patients without AL and $30.9 \pm 15.8 \mathrm{~Gy}$ in patients with $\operatorname{AL}(p=0.83)$.

Vande Walle et al. [16] studied the AL rates after 36 Gy and cisplatin/5-FU based NACRT followed by Ivor Lewis esophagectomy and intrathoracic anastomosis. AL was identified in 13\% (7/54) of patients. The median D50 of the GF was 33 Gy in patients with AL and 18 Gy in patients without AL $(p=0.024)$. Using receiver operating characteristic analysis, the D50 limit on the GF for AL was defined as 29 Gy. In our study, the median D50 was 40.44 Gy in patients with AL and $37.18 \mathrm{~Gy}$ in patients without AL.

However, other studies have shown conflicting reports. Koeter et al. [17] and Ermenc et al. [14] observed that the radiation dose to the GF did not influence the risk of AL. Koeter et al. [17] studied 41.4 Gy in 23 fractions and paclitaxel/carboplatin-based NACRT followed by transhiatal esophagectomy with cervical anastomosis using a gastric tube. AL was identified in 25.5\% (13/53) of the patients. In their multivariate analysis, they found no significant correlation between V20-40, mean dose to the $\mathrm{GF}$, and AL rates. Ermenc et al. [14] retrospectively analyzed records of 37 patients with Siewert I and II gastroesophageal junction cancer. A lower leak rate of $13.5 \%$ was reported, and no statistically significant relation with $D_{\text {mean }} / D_{\text {max }} /$ median dose received by the fundus was available for analysis. The median D50 was $45.6 \mathrm{~Gy}$ in patients with AL and 46.0 Gy in patients without AL. The current study also did not find a statistically significant relation between the $D_{\max }, D_{\text {mean }}, \mathrm{V} 20-35$ to the GF, and the occurrence of AL. 
Bang et al. [20] observed a higher incidence of AL when the anastomosis was placed inside the radiation field. The current study had 2 subjects with upper thoracic esophageal lesions, thus requiring inclusion of a supraclavicular field. These 2 patients, however, did not develop any $\mathrm{AL}$ after surgery.

In our study, gastric ischemic preconditioning was performed in 8 patients prior to NACRT by ligation of the left and short gastric vessels. Pham et al. [21] demonstrated, by immunohistologic analysis, a $29 \%$ increase in the microvascular density following short gastric vessel ligation and $67 \%$ increase after ligation of both short and left gastric vessels $(p<0.0001)$. A meta-analysis by Heger et al. [22] showed that there was no significant reduction in the incidence of leakage in the conditioned group compared to control patients (OR 0.76; 95\% CI: 0.51$1.13 ; p=0.18)$. However, the leaks were less severe, and the reoperation rates were lower ( 24.4 vs. $69 \%$; $p=0.001$ ) in preconditioned patients. In our study, AL was $2 / 8$ $(25 \%)$ in preconditioned versus $9 / 19(47 \%)$ in those who did not undergo preconditioning $(p=0.4)$, similar to the results reported by Zahedi et al. [23] and Nguyen et al. [24].

The major limitations of our study included the retrospective nature of the study and a relatively small sample size. We did not use respiratory gating in our patients. The position of the GF can vary considerably with respiratory motion $[25,26]$. Hence, the dose-volume parameters of the GF may not accurately represent the doses received during daily fractions of radiation. It is at best an approximation.

\section{Conclusion}

There was no significant negative impact of dose received by the GF in NACRT on the risk of AL in our study. Various dose parameters which have been postulated to have an impact on AL such as mean dose, V25, V30, V35, and D50 failed to show significance. Further studies with a larger sample size are required to clarify this issue.

\section{Acknowledgements}

The authors thank Dr. Salin K. Eliyas, MBBS, MD (Community Medicine-JIPMER), Department of Health Services, Kerala, India, for all statistical analyses. They also thank the Department of Radiation Physics, Jawaharlal Institute of Post Graduate Medical Education and Research (JIPMER), for radiotherapy planning of all the cases.

\section{Statement of Ethics}

This retrospective study has been approved by the Institutional Ethics Committee (Human Studies) at the Jawaharlal Institute of Post Graduate Medical Education and Research (JIPMER) JIP/IEC/2018/0117. In view of the retrospective nature of the study which does not reveal any patient's identity, waiver of consent has been granted by the institutional Ethics Committee.

\section{Conflict of Interest Statement}

The authors have no conflicts of interest to declare.

\section{Funding Sources}

No financial support has been sought/received from any funding body for this study.

\section{Author Contributions}

Dr. Nikhila Radhakrishna: study concepts, study design, data acquisition, analysis, and interpretation, and manuscript preparation. Dr. Shyama Prem Sudha: study concepts, study design, data analysis and interpretation, and manuscript preparation, editing, and review. Dr. Raja Kalayarasan: study concepts, data analysis and interpretation, and manuscript editing and review. Dr. Prasanth Penumadu: study concepts, data analysis and interpretation, and manuscript editing and review.

\section{Data Availability Statement}

All data generated or analyzed during this study are included in this article.

References

1 Van Hagen P, Hulshof MC, van Lanschot JJ, Steyerberg EW, van Berge Henegouwen MI, Wijnhoven BP, et al. Preoperative chemoradiotherapy for esophageal or junctional cancer. N Engl J Med. 2012;366(22):2074-84.

2 Shapiro J, van Lanschot JJB, Hulshof MCCM, van Hagen $P$, van Berge Henegouwen MI, Wijnhoven BPL, et al. Neoadjuvant chemoradiotherapy plus surgery versus surgery alone for oesophageal or junctional cancer (CROSS): long-term results of a randomised controlled trial. Lancet Oncol. 2015;16(9): 1090-8.

3 Chan KKW, Saluja R, Delos Santos K, Lien K, Shah K, Cramarossa G, et al. Neoadjuvant treatments for locally advanced, resectable esophageal cancer: a network meta-analysis. Int J Cancer. 2018;143(2):430-7.

Radhakrishna/Sudha/Kalayarasan/ Penumadu
Gastrointest Tumors 2021:8:121-127

DOI: $10.1159 / 000513929$ 
4 Sjoquist KM, Burmeister BH, Smithers BM, Zalcberg JR, Simes RJ, Barbour A, et al. Survival after neoadjuvant chemotherapy or chemoradiotherapy for resectable esophageal carcinoma: an updated meta-analysis. Lancet Oncol. 2011;12(7):681-92.

5 Biere SSAY, Maas KW, Cuesta MA, van der Peet DL. Cervical or thoracic anastomosis after esophagectomy for cancer: a systematic review and meta-analysis. Dig Surg. 2011;28(1): 29-35.

6 Verstegen MHP, Bouwense SAW, van Workum F, Ten Broek R, Siersema PD, Rovers M, et al. Management of intrathoracic and cervical anastomotic leakage after esophagectomy for esophageal cancer: a systematic review. World J Emerg Surg. 2019 Apr 4;14:17.

7 Liu YJ, Fan J, He HH, Zhu SS, Chen QL, Cao RH. Anastomotic leakage after intrathoracic versus cervical esophagogastric anastomosis for esophageal carcinoma in Chinese population: a retrospective cohort study. BMJ Open. 2018;8:e021025.

8 Kassis ES, Kosinski AS, Ross P Jr, Koppes KE, Donahue JM, Daniel VC. Predictors of anastomotic leak after esophagectomy: an analysis of the society of thoracic surgeons general thoracic database. Ann Thorac Surg. 2013 Dec;96(6):1919-26.

9 Gronnier C, Tréchot B, Duhamel A, Mabrut JY, Bail JP, Carrere N, et al. Impact of neoadjuvant chemoradiotherapy on postoperative outcomes after esophageal cancer resection: results of a European multicenter study. Ann Surg. 2014;260(5):764-70; discussion 770-1.

10 Chen KN. Managing complications I: leaks, strictures, emptying, reflux, chylothorax. J Thorac Dis. 2014;6(S3):S355-63.

11 Briel JW, Tamhankar AP, Hagen JA, DeMeester SR, Johansson J, Choustoulakis E, et al. Prevalence and risk factors for ischemia, leak, and stricture of esophageal anastomosis: gastric pull-up versus colon interposition. J Am Coll Surg. 2004;198(4):536-41; discussion $541-2$.
12 Goense L, van Rossum PS, Ruurda JP, van Vulpen M, Mook S, Meijer GJ, et al. Radiation to the gastric fundus increases the risk of anastomotic leakage after esophagectomy. Ann Thorac Surg. 2016;102(6):1798-804.

13 Morita M, Masuda T, Okada S, Yoshinaga K, Saeki H, Tokunaga E, et al. Preoperative chemoradiotherapy for esophageal cancer: factors associated with clinical response and postoperative complications. Anticancer Res. 2009;29(7):2555-62.

14 Ermenc AS, Hadzic JB, Peressutti AJ, Anderluh F, Oblak I, Velenik V, et al. The impact of the radiation dose delivered to the fundus and the stomach on the incidence of anastomotic complications for patients with gastro-esophageal junction cancer treated with neoadjuvant chemoradiotherapy and surgery. Int J Radiat Oncol Biol Phys. 2019;105(1):E20910.

15 Koëter M, Kathiravetpillai N, Gooszen JA, van Berge Henegouwen MI, Gisbertz SS, van der Sangen MJ, et al. Influence of the extent and dose of radiation on complications after neoadjuvant chemoradiation and subsequent esophagectomy with gastric tube reconstruction with a cervical anastomosis. Int J Radiat Oncol Biol Phys. 2017;97(4):813-21.

16 Vande Walle C, Ceelen WP, Boterberg T, Vande Putte D, Van Nieuwenhove Y, Varin $\mathrm{O}$, et al. Anastomotic complications after Ivor Lewis esophagectomy in patients treated with neoadjuvant chemoradiation are related to radiation dose to the gastric fundus. Int J Radiat Oncol Biol Phys. 2012;82(3): e513-9.

17 Koeter M, van der Sangen MJ, Hurkmans CW, Luyer MD, Rutten HJ, Nieuwenhuijzen GA. Radiation dose does not influence anastomotic complications in patients with esophageal cancer treated with neoadjuvant chemoradiation and transhiatal esophagectomy. Radiat Oncol. 2015;10:59.

18 Wu AJ, Bosch WR, Chang DT, Hong TS, Jabbour SK, Kleinberg LR. Expert consensus contouring guidelines for intensity modulated radiation therapy in esophageal and gastroesophageal junction cancer. Int J Radiat Oncol Biol Phys. 2015 Jul 15;92(4):911-20.
19 Low DE, Alderson D, Cecconello I, Chang AC, Darling GE, D'Journo XB, et al. International consensus on standardization of data collection for complications associated with esophagectomy: esophagectomy complications consensus group (ECCG). Ann Surg. 2015 Aug;262(2):286-94.

20 Bang A, Broomfield JA, Chan J, Alyamani N, Crnic A, Gilbert S, et al. Radiation dose mapping and anastomotic complications after trimodality therapy for esophageal cancers. Clin Transl Radiat Oncol. 2019;15:76-82.

21 Pham TH, Melton SD, McLaren PJ, Mokdad AA, Huerta S, Wang DH, et al. Laparoscopic ischemic conditioning of the stomach increases neovascularization of the gastric conduit in patients undergoing esophagectomy for cancer. J Surg Oncol. 2017;116(3):391-7.

22 Heger P, Blank S, Diener MK, Ulrich A, Schmidt T, Büchler MW, et al. Gastric preconditioning in advance of esophageal resection-systematic review and meta-analysis. J Gastrointest Surg. 2017;21(9):1523-32.

23 Zahedi M, Ganai S, Yetasook AK, Talamonti M, Ujiki MB, Carbray J, et al. Tu1767 Laparoscopic ischemic conditioning as a modality to reduce gastric conduit morbidity following esophagectomy. Gastroenterology. 2012; 142(5):S-1094.

24 Nguyen NT, Nguyen XM, Reavis KM, Elliott C, Masoomi H, Stamos MJ. Minimally invasive esophagectomy with and without gastric ischemic conditioning. Surg Endosc. 2012; 26(6):1637-41.

25 Watanabe M, Isobe K, Uno T, Harada R, Kobayashi $\mathrm{H}$, Ueno $\mathrm{N}$, et al. Intrafractional gastric motion and interfractional stomach deformity using CT images. J Radiat Res. 2011; 52(5):660-5.

26 Liu F, Yorke E, Huguet F, Gig M, Goodman KA. Dosimetric benefits of respiratory gating for gastroesophageal junction tumors. Int J Radiat Oncol Biol Phys. 2012;84:S796-S797.
Impact of Radiation Dose to Gastric Fundus upon Anastomotic Leak
Gastrointest Tumors 2021;8:121-127 